\title{
Mothers Satisfied From Quality of Care Given During Cesarean Delivery in Public and Private Hospitals of Tabriz, Iran
}

\author{
Fahimmeh Sehaty ${ }^{1}$, Sahar Azari $^{2^{*}}$, Hosseyn Ebrahimi ${ }^{2}$
}

\begin{abstract}
Objectives: The aim of this study was to assess the quality of cesarean care in regard to physical, emotional and ethical aspects among mothers who had recently delivered by cesarean section.

Materials and Methods: By using quota sampling method and questionnaire tool, 392 mothers who had been hospitalized for cesarean section in public and private hospitals of Tabriz, were selected. SPSS version 13, descriptive statistics, independent $t$ test, analysis of variance (ANOVA) and correlation tests were used for data analysis.

Results: Findings indicated that the rate of mothers' satisfaction in labor and post-partum stages in the ethical and physical dimensions were highest in both kinds of hospitals. The analysis of data showed significant difference between mothers' satisfaction with all aspects of care in the public and private hospitals $(P<0.001)$.

Conclusion: The results showed that mothers were more satisfied of physical and ethical dimensions, but emotional dimension of care in both kinds of hospitals was low so we should try to raise the quality of this aspect of caring.

Keywords: Cesarean section, Personal Satisfaction, Quality of health care
\end{abstract}

\section{Introduction}

Patient satisfaction is an imperative health care outcome (1). Its assessment has become part and parcel of hospital care quality monitoring and improvement programs (2). A review of the literature revealed that satisfaction is an important component of evaluation of a model of care (3), although it is a very individual, subjective, multifaceted concept, making it difficult to measure and interpret $(3,4)$. Patient satisfaction is the most important concept in medical care, because patients/clients satisfaction and dissatisfaction could create different responses in regard to medical services and cares. Satisfied patients/clients generally accept and follow up the treatment and recommend the others to do the same $(4,5)$. Patient satisfaction with nursing services gains even more importance, since owing to the nature of nursing practice, patients may judge the overall quality of hospital services on the basis of their perceptions of the nursing care received (6).

It is clear that maternal satisfaction is multidimensional and is influenced by both medical and social (emotional and ethical) factors. It is a complex psychological response to childbirth. It is much mentioned, but often poorly defined. Mothers have different views about childbirth experience at the same time. Women's satisfaction can be divided empirically into three independent dimensions. The first (fulfillment/delight) identifies the extent to which feelings of enthusiasm, happiness, excitement and delight are associated with childbirth. The second (distress) con- cerns the more passive, emotional responses, and contrasts feelings of relaxation with those of anxiety and panic (7). Childbirth can be regarded as a developmental crisis that engenders considerable stress for most women. Stress is increased when the birth occurs by cesarean section (8). Cesarean delivery is still prevalent, particularly in low-income countries (9). It is involves surgical delivery through incisions given in the abdominal and uterine walls. Compared to women delivering vaginally, women undergoing cesarean sections experience more pain and stress during childbirth. Women who deliver by cesarean section also worry comparatively more about the baby's condition during labor and experience more fear during delivery. The importance of emotional supporting is indicated (10). It is related to longer and more difficult postpartum recovery, a greater likelihood of obstetric complications and surgical delivery subsequently and worry comparatively more about the baby's condition during labor $(10,11)$. The third factor (difficulty) measures physical discomfort, including pain and exhaustion. These three components are independent; that is, whether a mother experienced physical discomfort and pain is no guide to how satisfied she is on one of the other dimensions (7).

Some factors that influence satisfaction, are related to aspects of the caring relationship. These include an attentive attitude by the care provider, time taken for care including waiting time and time taken with the woman, the provision of information and communication continuity of 
care (emotional and ethnical aspect of satisfaction) $(3,7)$. Overall quality maternal care is defined as an appropriate, satisfactory, low-cost and accessible service that makes women capable of choosing a healthy life (4). We can categorize hospital care services to private and public hospitals. The public ones are controlled by the government and people are not required to pay much money (12). In a public hospital, patient satisfaction is dependent on several factors in addition to surgical results. It is the way you talk to the patient, the degree of importance that is given to his or her problem, the amount of time you spend with them, the amount that you handle personally rather than delegating it to your juniors and the way you handle the relatives. Other peculiar factors are also seen from time to time (13).

Although cesarean delivery is popular in developing countries but there are not sufficient research on 'patient' satisfaction, in our country. Patients' evaluation of care has become a prominent method of assessing the quality of health care services. Our aim was to assess the quality of cesarean care in physical, emotional and ethical dimensions in public and private hospitals of Tabriz, Iran.

\section{Materials and Methods}

This study was descriptive-comparative in nature with the participants being 392 women who had cesarean section because of medical reasons in public and private hospitals of Tabriz. Sample size was chosen according to related researches (14). Quota sampling was used for determining the sample size. The study of the rate of cesarean section was done during the first 6 months of the year 2008 and the mean rate for each month was obtained. Finally, 184 and 208 women were recruited for the study from the public and private hospitals, respectively. The sample selection criteria were mothers who did not have any recognized history of medical and mental diseases and those who did not undergo elective cesarean section. Also, all participants spent at least 2 hours in the labor wards.

A simple, qualitative, semi-structured researcher-administered questionnaire was used for data collection. It was developed based on different studies. The questionnaire included two sections; the first part focused on assessment of demographic data and obstetric history and the second one contained three parts: assessment of physical satisfaction before and after cesarean section with 35 items (14 questions about labor and 21 ones about after delivery), emotional satisfaction with 17 items (8 questions about labor and 9 ones about after delivery), and ethical satisfaction with 28 items (14 questions about labor and 14 ones about after delivery). This questionnaire was provided with questions based on a Likert scale of 1 to 5 . For the systematic content analysis, patients' comments in response to specific questions were evaluated and classified as satisfied, extremely satisfied, negative (when explicitly or implicitly indicated dissatisfaction), extremely negative or neutral, lastly changed to 4 parts: omitted neutral group (the group which did not have any idea). Then the data were split into two groups, satisfied and not satisfied. To- tal scores were calculated and presented as percentages. The questionnaires were reviewed by 10 professors of the university to assess content validity, and Cronbach alpha coefficient of 0.8 demonstrated reliability of the questionnaire for assessing clients' satisfaction. Statistical analysis of quantitative data was carried out using the SPSS version 13 , and descriptive statistics, independent $t$ test, analysis of variance (ANOVA), and correlation tests were used for data analysis. Mean values (M) and standard deviations (SD), as well as ranges of values were reported.

\section{Results}

The quality of provided care to 392 normal pregnant women was assessed in the study. The majority of women (21.8\%) were 21-25 years old and primipara (45.9\%). The majority (92.9\%) were housewives, $40.6 \%$ had high education and $94.4 \%$ experienced planned pregnancy. Gestational age in most of them was more than 37 weeks and $48.2 \%$ underwent cesarean section in the morning time. $17.6 \%$ did not recommend hospital to other ones and $17.3 \%$ declared referring to the same center because most of them (61.7-62.3\%) were not satisfied with the care providers. Table 1 shows the reasons of not referring to the same center.

There was significant relationship between physical satisfaction with number of pregnancy $(P=0.04)$, number of live children $(P=0.03)$, number of dead children $(P=0.03)$, emotional satisfaction with woman's education $(P=0.002)$, time of delivery $(P=0.01)$, ethical satisfaction with woman's education $(P=0.01)$, job $(P=0.005)$ and pregnancy age $(P=0.001)$. The highest rate of satisfaction was related to physical aspect in public and private hospitals. Satisfaction rates in different aspects in public and private hospitals have been shown in Figures 1-3.

The rate of total satisfaction in private hospitals was higher than public hospitals and also the level of physical, emotional and ethical satisfaction was statistically meaningful between public and private hospitals $(P<0.001$; Table 2$)$.

\section{Discussion}

The present study was an attempt to assess the level of satisfaction of the patients with the various aspects of health care in the private and public hospitals of Tabriz, Iran and to evaluate its quality. Yet, the findings of the survey were

Table 1. Reasons of not Proposing the Hospitals to Other Ones and not Referring to the Same Center

\begin{tabular}{lll}
\hline Reasons & Condition & No. (\%) \\
\hline $\begin{array}{l}\text { Unsatisfied with } \\
\text { care providers }\end{array}$ & Not proposing hospital to others & $69(62.3)$ \\
Unsatisfied with & Not referring to same center & $68(61.7)$ \\
costs & Not referring to same center & $68(7.4)$ \\
$\begin{array}{l}\text { Unsatisfied with } \\
\text { facilities and }\end{array}$ & Not proposing hospital to others & $69(7.2)$ \\
equipments & Not referring to same center & $68(7.4)$ \\
$\begin{array}{l}\text { Unsatisfied with } \\
\text { service quality }\end{array}$ & Not proposing hospital to others & $69(23.2)$ \\
& & $68(23.5)$ \\
\hline
\end{tabular}




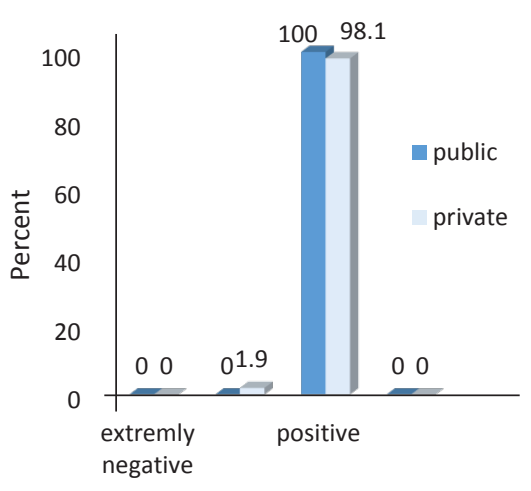

Satisfaction rate

Figure 1. Physical Satisfaction Rates During Labor and Postoperative Stage in Women Who Had Cesarean Section in Public and Private Hospitals.

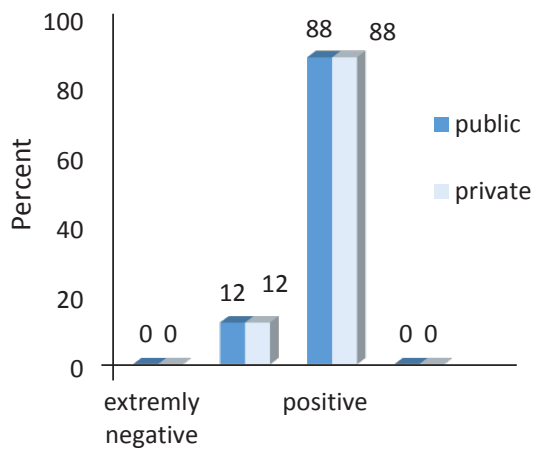

Satisfaction rate

Figure 2. Emotional Satisfaction Rates During Labor and Postoperative Stage in Women Who Had Cesarean Section in Public and Private Hospitals.

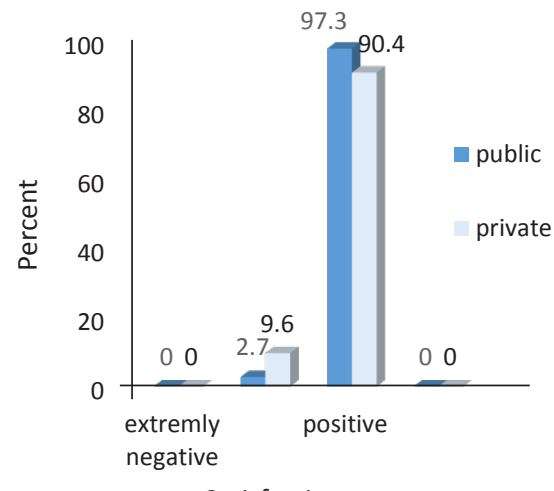

Satisfaction rate

Figure 3. Ethical Satisfaction Rates During Labor and Postoperative Stage in Women Who Had Cesarean Section in Public and Private Hospitals

quite helpful if they were transformed into schedules for improving the quality of health care system. Evidence from this study suggests that the highest rate for mothers' satisfaction with delivery by cesarean was reported by $100 \%$ of the respondents in public hospitals and $96.2 \%$ in private ones. Some studies confirm our point $(15,16)$. This
Table 2. Comparing the Satisfaction Rates in Different Aspects in Women Who Had Cesarean Section in Public and Private Hospitals

\begin{tabular}{lccccc}
\hline \multirow{2}{*}{ Satisfaction } & \multicolumn{2}{c}{ Hospital Public } & \multicolumn{2}{c}{ Hospital Private } & \multirow{2}{*}{$\boldsymbol{P}$ value } \\
\cline { 2 - 5 } & Mean & SD & Mean & SD & \\
\hline Physical & 116.2 & 4.0 & 114.7 & 3.3 & $<0.000$ \\
Emotional & 58.3 & 3.2 & 59.7 & 4.0 & $<0.000$ \\
Ethical & 89.5 & 2.6 & 88.5 & 2.4 & $<0.04$ \\
Total & 466.3 & 11.2 & 465.5 & 8.4 & 0.41 \\
\hline
\end{tabular}

high level of satisfaction in our study might result from the ignorance of mothers about patient rights.

The satisfaction rate about the ethical and physical categories were high in both kind of hospitals. This is consistent with other studies $(14,17)$. Evidence from this study suggests that physical satisfaction was high in private and public hospitals. In Mirmolaei et al study, in hospitals related to the medical university of Tehran, Iran, Shahid Beheshti and Social Security Institute, $68.75 \%$ of mothers had full satisfaction about the physical support in labor and delivery room (18), which are not the same as this study and the level of it was higher in ours. Environmental, cultural, social and economic difference between samples of our study and Mirmolaei et al study can affect the maternal satisfaction directly.

This is consistent with other studies $(14,17)$. This study has shown that ethical satisfaction during labor was lower than post-operative stage. Ethical satisfaction in labor (69.3\%) was lower than post-partum phase in educational and non-educational hospitals (14). Unfortunately we could not find more articles about this aspect of satisfaction. It should be noted that the patient is the central figure around whom our day revolves. She is the reason we are there. The patient needs informational care just as physical. Nurses should talk as gently as possible. Our findings revealed emotional satisfaction during labor was lower than post-operative stage in both kind of hospitals $(14,16)$. In Simbar et al study the lowest level of satisfaction was about emotional aspect of satisfaction during labor phase at university teaching hospitals (4). Hildingsson and Radestad defined emotional satisfaction rate as $77 \%$, which was lower than physical aspect (16). Results of Mirmolaei et al study in 2008 showed that in hospitals related to the medical university of Tehran, Iran, Shahid Beheshti and Social Security Institute, $79.5 \%$ of the mothers were fully satisfied with emotional supports. The results of their study are inconsistent with ours about the caesarian delivery (18).

There was significant association between physical satisfaction with number of pregnancy, number of live children, and number of dead children, emotional satisfaction with woman's educational status, and time of delivery, and ethical satisfaction with woman's education, job, and pregnancy age. Some trainings resist our finding $(15,16,19)$. The rate of physical, emotional, and ethical satisfaction is shown in Figures 1-3. Difference between public and 
private hospitals in all aspects was statistically meaningful $(P<0.001)$. In a study based on hospital service quality evaluation and the patients' satisfaction in London, Owusu-Frimpong et al showed that the type of the hospital is the main factor in satisfaction of women in caring system (20). Satisfaction is a complex concept. It involves either a positive attitude or affective response to an experience, as well as a cognitive evaluation of the emotional response (21). This study declared that the difference between public and private hospitals in all aspects was statistically meaningful (22). Periodic assessment of the quality of care delivered together with feedback to the system on the overall quality of care was necessary.

\section{Conclusion}

Our findings have important implications for hospital owners, managers, government officials, academics, and other related parties. The hospitals need to organize training sessions based on the critical importance of service quality and the crucial role of inpatient satisfaction in the health care industry. In recent decades, the importance of measuring satisfaction with health care has been recognized. Patients' views are being used by health care managers in assessing the quality of care and by policy makers in making decisions about the organization and provision of health services.

\section{Limitations}

In our study, we did not consider the level of patient knowledge about their rights, so it is suggested to assess patient rights and satisfaction simultaneously.

\section{Ethical Issues \\ Not applicable}

\section{Conflict of Interests}

We would like to thank Tabriz University of Medical Sciences, Iran.

\section{Financial Support}

The researchers received no financial support or grant from any funding agency in the public and commercial sectors.

\section{Acknowledgments}

We thank all mothers who helped us in this study.

\section{References}

1. Howard M, Goertzen J, Hutchison B, Kaczorowski J, Morris K. Patient satisfaction with care for urgent health problems: a survey of family practice patients. Ann Fam Med. 2007;5(5):419-24. doi: 10.1370/ afm.704.

2. Hendriks AA1, Smets EM, Vrielink MR, Van Es SQ, De Haes JC. Is personality a determinant of patient satisfaction with hospital care? Int J Qual Health Care. 2006;18(2):152-8. doi: 10.1093/intqhc/mzi102.

3. Harvey S, Rach, D, Stainton MC, Jarrell J, Brant
R. Evaluation of satisfaction with midwifery care. Midwifery. 2002;18(4):260-7.

4. Simbar M, Alizadeh Dibazari Z, Abed Saeidi J, Alava Majd H. Assessment of quality of care in postpartum wards of Shaheed Beheshti medical university hospital. Shaheed Beheshti Univ Med Sci J. 2005;10(43):45-9.

5. Page LA. The new midwifery science and sensitivity in practice. London: Churchill Livingstone; 2000. p. 106.

6. Merkouris A, Papathanassoglou ED, Lemonidou C. Evaluation of patient satisfaction with nursing care: Quantitative or qualitative approach. Int J Nurs Stud. 2004;41(4):355-67.

7. Robinson PN, Salmon P, Yentis SM. Maternal satisfaction. Int J Obstet Anesth. 1998;7(1):32-7.

8. Izbizky GH, Minig L, Sebastiani MA, Otano L. The effect of early versus delayed post caesarean feeding on women's satisfaction: a randomized controlled trial. BJOG. 2008;115(3):332-8. doi: 10.1111/j.14710528.2007.01591.x.

9. Tengilimoglu D, Kisa A, Dziegielewski SF. Patient satisfaction in Turkey: Differences between Public and Private Hospitals. J Community Health. 1999;24(1):73-91.

10. Lobel M, DeLucab RS. Psychosocial squeals of cesarean delivery: review and analysis of their causes and implications. Soc Sci Med. 2007;64(11):2272-84.

11. Nikolajsen L, Sorensen HC, Jensen TS, Kehlet H. Chronic pain following caesarean section. Acta Anaesthesiol Scand. 2004;48(1):111-6.

12. Mosaddeg rad A. Management of hospitals. Available from: http://www.hcpm.blogfa.com/cat-7.aspx. Accessed April 30, 2013.

13. Jagannathan M. Patient satisfaction and ethics in a public hospital practice. Indian J Plast Surg 2008;41(2):107-9. doi: 10.4103/0970-0358.44919.

14. Nagizadeh S. Assessment of mothers' satisfaction with the care of maternal care during hospitalization for labor and delivery in educational and noneducational maternity hospitals of Tabriz. Nurs Midwifery J Tabriz. 2009;13:29-36.

15. Enabudoso E, Isara AR. Determinants of patient satisfaction after cesarean delivery at a university teaching hospital in Nigeria. Int J Gynaecol Obstet. 2011;114(3):251-4. doi: 10.1016/j.ijgo.2011.03.010.

16. Hildingsson I, Radestad I. Swedish women's satisfaction with medical and emotional aspects antenatal care. J Adv Nurs. 2005;52(3):239-49.

17. Simbar M, Ghafari F, Zahrani ST, Majd HA. Assessment of quality of midwifery care in labour and delivery wards of selected Kordestan Medical Science University hospitals. Int J Health Care Qual Assur. 2009;22(3):266-77.

18. Mirmolaei ST, Khakbazan Z, Kazemnejad A, Azari M. Prenatal care utilization rate and patient satisfaction. Hayat. 2008;13(2):31-40.

19. Waldenstrom U, Hildingsson I, Rubertsson C, 
Radestad I. A negative birth experience: prevalence and risk factors in a national sample. Birth. 2004;31(1):17-27.

20. Owusu-Frimpong N, Nwankwo S, Dason B. Measuring service quality and patient satisfaction with access to public and private healthcare delivery. International Journal of Public Sector Management. 2010;23(3):203-20. doi: 10.1108/09513551011032455.
21. Hodnet ED. Pain and women's satisfaction with the experience of childbirth: a systematic review. Am J Obstet Gynecol. 2002;186(5 Suppl):S160-72.

22. Bazant E. Women's place of delivery and experience of quality in delivery care: a quantitative and qualitative study in Nairobi's informal settlements $[\mathrm{PhD}$ dissertation]. Baltimore, Maryland: Johns Hopkins University; 2008.

Copyright ( 2016 The Author(s); This is an open-access article distributed under the terms of the Creative Commons Attribution License (http://creativecommons.org/licenses/by/4.0), which permits unrestricted use, distribution, and reproduction in any medium, provided the original work is properly cited. 